\title{
Influência: um problema Político-Terapêutico na Genealogia da Psicanálise
}

\section{Influencer: a Politic-Therapeutic problem in Psychoanalysis Genealogy}

\section{Influencia: un problema Político-Terapéutico en la Genealogía del Psicoanálisis}

\author{
Tatiane de Andrade* \\ Universidade Federal do Rio de Janeiro - UFRJ, Rio de Janeiro, Rio de Janeiro, Brasil
}

\begin{abstract}
RESUMO
O presente artigo tem por objetivo traçar uma genealogia possível da técnica psicanalítica apontando para a importância das dimensões histórica, política e social na construção da psicanálise. A partir do fenômeno do magnetismo animal, postulado por Franz Anton Mesmer, no século XVIII, passando pela hipnose e pela sugestão até alcançarmos a transferência na psicanálise, buscaremos remontar a influência como pressuposto éticopolítico que perpassa e, mesmo, possibilita todas essas práticas.
\end{abstract}

Palavras-chave: influência, psicanálise, transferência, libido, política.

\begin{abstract}
The present article aims to delineate a possible genealogy of the psychoanalytical technique indicating the importance of the historical, political and social dimensions in the construction of the psychoanalysis. From the animal magnetism phenomenon, postulated by Franz Anton Mesmer, in the eighteenth century, moving to hypnosis and suggestion until achieving the transference in psychoanalysis, we seek reassemble the influence as ethical-politic presuppose that passes through, and yet, makes possible all these practices.

Keywords: influence, psychoanalysis, transference, libido, politic.

\section{RESUMEN}

El artículo tiene por objectivo trazar una genealogía possible de la técnica psicoanalítica marcando la importancia de las dimenciones históricas, política y sociales en la construcción de la psicoanálisis. A partir del fenômeno del magnetismo animal, propuesto por Franz Anton Mesmer, en siglo XVIII, pasando por la hipnosis y por la sugestión, hasta encuentrarmos la transferencia psicoanalítica, intentamos remontar la influencia como pressupuesto ético-político que atraviesa y possibilita todas esas practicas.

Palabras clave: influencia, psicoanalisis, transferencia, libido, política.
\end{abstract}




\section{Introdução}

No século XVIII, na França pré-revolução, ganhou corpo uma nova terapêutica proposta pelo médico Franz Anton-Mesmer (1734-1815). Inspirado nas teorias da gravitação universal, da eletricidade e do imã, Mesmer afirmava que, se era possível aos corpos celestes influenciar-uns aos outros, esse mesmo princípio deveria valer, também, para os corpos animais. Ao que surge batizado de magnetismo animal este princípio que ditava o funcionamento do organismo e as leis de inter-relação entre os corpos.

Como se alastrava a passos largos e provocava burburinhos na sociedade francesa, o rei Luís XVI (1754-1793) designou duas comissões, uma composta por membros da Academia de Ciências de Paris e outra comissão formada por membros da Academia de Medicina. Dentre os comissários notáveis estavam o químico AntoinLaurent Lavoisier (1743-1793), o astrônomo e político Jean Sylvain Bailly (1736-1793), o físico Ignace Guillotin (1738-1914) - inventor da guilhotina, a qual, nove anos depois, decapitou o monarca, os companheiros de comissão Bailly e Lavoisier, e, posteriormente, o próprio Guillotin -, o cientista e diplomata Benjamin Franklin (17061790) e o botânico Antoine Laurent de Jussieu (1748-1836). O objetivo da comissão era claro: inquirir a validade da terapêutica mesmérica (Ellenberger, 1970; Chertok \& Stengers, 1989; Zweig, 2017). Após assistirem a algumas sessões, tornou-se inconteste a influência que o magnetizador exercia sobre os enfermos e o contágio que se alastrava entre eles, de modo que o objetivo primeiro da comissão - verificar a validade do método de Mesmer - desviou-se para a busca do "algo fundamental" (Chertok \& Stengers, 1989, p. 25) que possibilitava os fenômenos observados.

$O$ resgate deste conhecimento se dará, primeiro e de forma tímida, no século XIX, com o médico escocês James Braid (1795-1860), ao propor, a partir de alguns retalhes do magnetismo, a hipnose. Posteriormente, Jean Martin Charcot (1825-1893), famoso médico francês, usará da hipnose com a finalidade de compreender o estado histérico, ato que opera uma mudança nas formas de entendimento tanto da histeria quanto da hipnose, resgatando-as do limbo a que estavam condenadas. Até então, a histeria se impunha como obstáculo à neuropsiquiatria, visto que não se achava qualquer lesão de ordem orgânica que pudesse justificá-la no quadro das doenças nervosas (Birman, 2012).

Já Hyppolite Bernheim (1940-1919), herdeiro intelectual de Ambroise-August Liébout (1823-1904), médico da Escola de Nancy, a qual se dedicava ao estudo da sugestão, considerava os fenômenos da hipnose como decorrentes de efeitos psíquicos, efeitos de ideias provocadas, de modo que seria resultante da sugestão e não de estímulos externos (Ellenberger, 1970). A teoria de Nancy rompia em 
definitivo com qualquer causa anatômica na histeria, a qual era definida, por seu turno, como "efeito da sugestionabilidade sobre o sujeito" (Birman, 2012, p. 55).

Será com essa gama de enunciados e posições que Sigmund Freud (1856-1939) tentará firmar a psicanálise no seio da ciência, aquela mesma cuja condenação, um século antes, vetou o magnetismo do meio científico. Para tanto, a noção de realidade material, acessível através de um método objetivo, baseado nos princípios causais, cede espaço à construção de uma nova noção de realidade, agora psíquica, cujo acesso se daria por meio da linguagem. Pensar uma outra realidade - ou pensar a realidade em outros termos - recoloca a importância do outro na constituição do psíquico e traz de regresso conceitos caros à ciência desde o mesmerismo, como desejo, imaginação e influência, possíveis mediante a ação de uma energia de caráter psíquico, a qual investiria os diversos objetos e seria determinante para o estabelecimento da relação terapêutica.

A escolha epistêmica, política e terapêutica de Freud fez uma aposta na relação do sujeito como o outro como norteadora da teoria nascente. Assim, coloca-se em questão uma problemática fundamental que caracteriza o homem na sua existência, a saber, o poder que um homem tem de influenciar um outro, não através de um raciocínio lógico dedutivo, antes pela relação afetiva que os une.

Vale lembrar que a influência se colocará como questão tanto à técnica psicanalítica, que, no campo da clínica, faz-se necessária a dissolução da transferência para romper com a "tirania da sugestão" (Freud, 1996i/1921, p. 95), a qual amarra o sujeito ao seu desejo de ser sugestionado e submisso, quanto para o entendimento dos "efeitos de massa" (Freud, 2017a/1890, p. 28), observados em vários contextos sociais, das igrejas aos exércitos, cuja identificação com as figuras de poder expõe os diferentes grupos à obediência cega e, por conseguinte, à dominação (Freud, 1996i/1921).

\section{Da cuba mesmérica ao poder da sugestão}

Não podemos impedir-nos de reconhecer....um grande poder que agita os doentes e os domina, e do qual o magnetizador parece ser o depositário...Todos se submetem àqueles que os magnetiza; por mais que estejam num aparente torpor, sua voz, um olhar ou um sinal os retira disso...os membros da comissão que, no conjunto dos doentes em crise, havia sempre muitas mulheres e poucos homens; que essas crises levavam uma ou duas horas para se estabelecer; e que, a partir do momento em que uma se instalava, todas as demais começavam sucessivamente e em pouco tempo (Bailly como citado em Chertok \& Stengers, 1989, p. 27) 
Eis um trecho do relato produzido por uma das comissões composta por intelectuais da Academia de Ciências de Paris, dentre eles Lavoisier, designada pelo rei Luís XVI para descobrir o que estava por trás do fenômeno do magnetismo animal que se disseminava a passos largos na França do século XVIII. Tal fenômeno, proposto pelo médico austríaco Franz-Anton Mesmer, propunha a existência de um fluido universal de poder curativo que perpassava os corpos, de igual maneira, através da concentração e comunicação. A partir desta asserção podemos extrair duas premissas básicas: primeira, que os corpos se comunicam; segunda, que existe algo de fundamental que possibilita tal comunicação.

Foi no encalço da validade destas proposições que se lançaram as duas comissões reais em 1784: uma representante da Sociedade dos Médicos; a outra, da Academia de Ciências de Paris (Chertok \& Stengers, 1989; Zweing, 2017), cujo objetivo era reconhecer a influência de um corpo sobre o outro e, uma vez reconhecida essa influência, descobrir o quê que possibilitava tal contágio, desviandose, deste modo, do objetivo primeiro da comissão que se restringia a validar, ou não, a importância terapêutica do magnetismo.

As bases do magnetismo animal assentavam-se no princípio da Gravitação Universal, desenvolvido por Isaac Newton (1642-1727), segundo o qual os planetas se afetam mutuamente em suas órbitas e que os demais astros, tal qual o sol e a lua, causam e dirigem fluxo e refluxo tanto no mar quanto na atmosfera (Figueiredo, 2005). A partir dessas premissas, Mesmer (2005/1779) sustentou a tese segundo a qual "o corpo animal, estando submetido à mesma ação, experimenta também um forte fluxo e refluxo" (p. 303). Atração e repulsa como leis que se estendem, inclusive, aos corpos animais, logo aos seres humanos, ao que surge batizado de magnetismo animal a propriedade destes corpos que os tornam "suscetíveis à influência dos corpos celestes e da ação recíproca daqueles que o cercam" (p.329).

Segundo as proposições do médico, "existia uma influência mútua entre os corpos celestes, a Terra e os corpos animados" (Mesmer, 2005/1779, p. 328), e que tal influência seria decorrente da existência de um fluido universal capaz de "receber, propagar e comunicar todas as impressões do movimento" (p. 328), submetido que está às leis mecânicas. Por conseqüência, seria como derivado do fluido universal que o fluido magnético animal, como propriedade dos corpos animais, responderia pela influência entre corpos distintos.

Deste modo, para Mesmer (2005/1779), "todos os corpos eram, assim como o imã, suscetíveis da comunicação deste princípio magnético; esse fluido penetrava tudo; podia ser acumulado e concentrado como o fluido elétrico" (p. 309). Portanto, se os corpos influenciavam uns aos outros, quer partilhassem a mesma natureza 
ou não, já que derivados de um mesmo princípio, qual seja, o fluido, haveria algo de fundamental nesta influência que poderia ser transposto à cura médica.

A doença, entendida como resultante do desequilíbrio desses tantos fluidos que permeavam o corpo (Figueiredo, 2005; Monteiro \& JacóVilela, 2008), poderia ser sanada com o reequilíbrio destes mesmos fluidos, alcançado com o uso de imãs e da eletricidade. A terapêutica mesmérica, em seu início, consistia em dispor os enfermos no baquet, espécie de cuba, a fim de fazer circular a energia entre os corpos a partir da magnetização. Assim, ligados todos os doentes uns aos outros, haveria uma circulação do fluído, o despertar da crise e o consequente restabelecimento do equilíbrio entre eles.

As crises, descritas ora como rito, ora como transe, eram caracterizadas pela perda do controle dos músculos e feições, inundando o corpo que, após os violentos embates, repousava em abatimento. Após observar uma das sessões, assim as definiu um dos comissários:

Quando essa espécie de crise se prepara, o rosto vai-se afogueando gradativamente, o olhar torna-se ardente, e é esse sinal através do qual a natureza anuncia o desejo...Todavia, a crise continua e a visão se turva: é um sinal inequívoco da completa desordem dos sentidos. Essa desordem pode não ser percebida por aquela que a experimenta, mas não escapou ao olhar observador dos médicos. Tão logo esse sinal se manifesta, as pálpebras ficam úmidas, a respiração fica sôfrega, entrecortada, e o busto se eleva e se abaixa rapidamente; instalam-se convulsões, assim como os movimentos precipitados e bruscos, seja dos membros, seja do corpo inteiro. Nas mulheres vivas e sensíveis, o último grau, a conclusão da mais doce das emoções, é muitas vezes uma convulsão. A este estado sucedem-se a languidez e 0 abatimento, uma espécie de sono dos sentidos, que é um repouso necessário após uma intensa agitação (Bailly como citado em Chertok \& Stengers, 1989, p. 24/2, grifo nosso).

O que se verificava no recinto terapêutico era uma perfeita orquestração dos corpos e dos sentidos cujos movimentos eram alastrados e propagados por todos tão logo a crise se anunciasse em qualquer um dos participantes. Assim, será na importância do magnetismo animal inerente ao humano, em detrimento do magnetismo mineral e da eletricidade, que repousará o núcleo do mesmerismo, levando Mesmer, posteriormente, a abandonar a terapêutica com imãs e demais artefatos para se concentrar na influência que o magnetizador exercia sobre os sujeitos. "Entre a medicina e a magia das cubas, varetas e passes magnéticos, Mesmer 
descobre o poder da sugestão" (Monteiro \& Jacó-Vilela, 2008, p. 142).

Quanto às comissões designadas pelo rei da França, foram produzidos dois relatórios. Segundo os comissários, a imaginação seria o elemento secreto agente do magnetismo. Acrescentaram a este elemento dois outros de igual modo responsáveis pelos eventos observados, a saber, o toque e a imitação. Ou seja, para a comissão de Lavoisier, Guillotin, Franklin, Bailly e Jussieu o magnetismo não passava de um efeito da imaginação, possível mediante o toque do magnetizador, que influenciava o enfermo e o conduzia à crise, seguido da imitação dos demais componentes, produzindo 0 espetáculo mesmérico. Espetáculo este, diga-se de passagem, que não se restringia à cuba terapêutica e tirou o sono da aristocracia na França monárquica. Segundo os enviados do rei, a imaginação também atuava no palco, no exército e nas assembleias numerosas (Chertok \& Stengers, 1989). Operando por meios díspares, produzia efeitos semelhantes e anunciava o pavor das massas.

Deste modo, a fórmula do mesmerismo expunha uma tríade cara à ciência e ao contexto político-histórico da época: imaginação, influência, imitação. Uma vez reconhecida a influência que um indivíduo exercia sobre o outro, coube à comissão excluir os excessos, aparar as arestas e eliminar o que se colocava como risco social e como empecilho à ciência, cujo método exigia a observação do fenômeno puro. Ao alocar a questão do magnetismo animal nos domínios da imaginação se esgotaram as possibilidades de perguntas e reflexões necessárias ao propósito científico (Bachelard, $1996 / 1938$ ) e esta "se tornou um campo ao mesmo tempo morto e proibido, um campo de inércia científica que não merecia maiores atenções dos pesquisadores sérios" (Neubern, 2007).

Fato que nos interessa aqui, sobremaneira, é o trecho fundamental do relatório produzido pela comissão e mantido em segredo, apenas exibido ao monarca, em que se lia: "os doentes em estado de sonambulismo apresentam, muitas vezes, uma espécie de atração pelo operador que os fez adormecer" (Binet como citado em Chertok \& Stengers, 1989, p. 49). Ainda, segundo o documento, tal atração seria de natureza sexual.

Condenado no meio científico e social pelo que congregava de impuro e perigoso - imaginação, influência, imitação, "algo da ordem sexual" - o mesmerismo amargou um século de silenciamento.

\section{A queda do poder soberano e a constituição da modernidade}

A volta da influência como dispositivo terapêutico se dará a partir de um processo lento, marcado pelo contexto social e político. Assim, o hiato entre a condenação do mesmerismo e a retomada da influência 
a partir da categoria de hipnose não pode ser lido como período em que tais práticas estiveram ausentes do fazer médico. Antes, essas práticas continuavam exercendo fascínio, gerando apelos e curas, embora nas surdinas e nas alcovas, longe dos centros de poder (Ellenberger, 1970; Zweing, 2017/1930). Logo, ausentes, porque silenciadas.

O regresso do dispositivo da influência e seus devidos correlatos aos salões nobres do saber pode ser entendido restabelecendo as implicações e conexões com o momento histórico e político em que isso foi possível, a saber, a modernidade. De acordo com Foucault (1977/1963), a passagem da pré-modernidade para a modernidade investiu a medicina de poder e importância, de modo que experiências sociais passaram a ganhar uma leitura médica, promovendo uma medicalização do espaço social. Assim, o imperativo da salvação, ocaso da tradição cristã, cedeu espaço ao imperativo da cura, materializando a morte de deus, como a anunciou Nietzsche (2012/1882), e, no plano social, a morte do rei guilhotinado, como o fez a revolução francesa. Desta feita, a reativação das práticas hipnótico-sugestivas, na modernidade, pode ser entendida como efeito das transformações na economia simbólica do poder. O declínio da soberania e a decorrente horizontalização dos laços sociais impuseram a exigência de uma outra forma de governamentalidade (Birman, 2012), possível mediante a construção de consensos pelo viés da opinião pública.

O que está em jogo nesse momento histórico é o uso do mecanismo da influência como práxis, cujo objetivo último é a gestão da multiplicidade dos laços, vozes e demandas sociais. De outro lado, sem uma instância superior e transcendente que pudesse balizar a existência e as formas de se colocar no mundo, o sujeito, embora livre, viu-se desamparo, necessitando buscar em si e na autoorganização as bases para a construção da vida e do comum. É nesse cenário que a influência, como prática terapêutica, será retomada quase 70 anos depois da condenação de Mesmer, na França pósrevolução, pelo médico escocês James Braid. Sem varas magnetizadas e sem comissão, mas nem por isso menos suspeita, sob o nome de hipnose. Entretanto, as práticas hipnótico-sugestivas aguardarão um século para que a ciência permita seu (re)ingresso nos salões do saber constituído.

\section{Hipnose, sugestão}

O termo hipnose, de origem grega, deriva do termo Hypnos, que representa, na mitologia grega, o deus do sono. Irmão de Thanatos, deus da morte, e filho de Nix, a deusa da noite, a qual, por sua vez, é filha de kháos (Hesíodo, 1995/s.d., p. 91). Assim, Hypnos tem como 
princípio cosmogônico kháos, cuja linhagem "se marca pela chancela do Não-Ser, todas as formas de violência das potências negativas e destrutivas" (Torrano, 1995, p. 51), de modo que "os descendentes de Kháos não se unem procriativamente a ninguém" (p. 51), ao contrário dos descendentes de Éros, o outro princípio cosmogônico, "eles atuam [os descendentes de Kháos] como potências de cisão, de desagregação, da violência e da morte, pois assim se expressa 0 poder de Caos" (Torrano, 1995, p. 51). Daí, talvez, o porquê de a palavra hipnose ser circundada, em seu nascedouro e ainda nos tempos de hoje, por uma aura sombria.

O vocábulo, transposto para o fazer médico, foi utilizado pela primeira vez no século XIX, por James Braid, que buscou referir-se à hipnose como o estado de sono do sistema nervoso (Ellenberger, 1970), daí a busca, na mitologia grega, de um termo que fosse correlato. Entretanto, Braid, que havia cunhado a expressão em 1843 (Chertok \& Stenger, 1989), logo se apercebeu do equívoco, já que, ao contrário do sono, na hipnose se verificava intenso funcionamento mental, o que invalidava a correlação entre os dois estados no campo científico.

Segundo Zweig (2017/1930) a ideia de que o estado hipnótico era algo próximo ao sono foi tomada de empréstimo do marquês Armand Chastenet de Puységur (1795- 1860), aluno e discípulo de Mesmer. Pyuségur, nobre e dado à caridade, usava a terapêutica magnética para curar inúmeros camponeses, pessoas sem recursos financeiros, alheias às incontáveis disputas que envolviam o método magnético, e que lançavam ao mesmerismo um último apelo contra os males que as assolavam. Fora do campo médico e longe dos olhares e controle das academias de ciência, Pyuségur, tentando provocar a crise que anunciava a cura, observou, em um dos enfermos, não os ataques esperados, antes um sono profundo.

Excitado com o acontecimento que fugia à regularidade, o conde replicou a experiência incontáveis vezes. Encontrou um segundo estado de consciência que permitia ao enfermo, e a vários outros, executar ações comuns do cotidiano mesmo em aparente estado de sono. E mais: os sonâmbulos eram capazes de executar em vigília ordens que thes eram transmitidas quando adormecidos sem, no entanto, lembrar-se do que ocorrera naquele estado (Figueiredo, 2005; Zweig, 2017/1930).

Assim, Puységur propôs que a relação terapêutica se baseava em algo de natureza psicológica e não fluídica, como acreditavam os magnetizadores (Chertok \& Stengers, 1989; Roudinesco \& Plon, 1998). A partir desse novo princípio causal, que excluía a existência de algo material pelo qual fosse possível a indução de estados, colocou-se a sugestão no cerne da problemática. Se, em Mesmer, era posto como premissa um fluido que emanava da figura do magnetizador, pela nova situação "tudo se passava na mente do 
sujeito" (Chertok \& Stengers, 1989, p. 47). As ordens pós-hipnóticas e a memória que resistia ao transe abriram o campo de compreensão para os fenômenos do magnetismo e da sugestão e questionaram o primado da consciência na vida dos homens.

Deste modo que Braid fará uso da sugestão, agora designada de hipnose, para conduzir os pacientes a um estado de sono, cuja característica era a ausência de consciência com efeito anestésico, a fim de evitar dor e desprazer. Portanto, em tal contexto, o uso da hipnose não estava posto como terapêutico, uma vez que seu alcance se restringia ao efeito paliativo do sofrimento físico ou psíquico, cujo foco era a sensibilidade (Bocca, 2011).

Das três grandes teorias que se propuseram a explicar os fenômenos de natureza hipnótica destacam-se as teorias de Mesmer, Jean Martin Charcot e Hyppolite Bernheim. Para Mesmer, como exposto anteriormente, os fenômenos hipnóticos seriam resultantes da passagem de fluidos do hipnotizador para o hipnotizado.

Segundo a vertente fisiológica, entretanto, cujo expoente fora Charcot, à hipnose correspondia o estado modificado do sistema nervoso causado por estímulos externos, mecanismo igual ao encontrado na histeria. O médico francês desprezava a influência de qualquer "ideia" na origem do fenômeno e marcava como base da hipnose uma predisposição do sistema nervoso. Utilizou-se da hipnose de modo muito específico: para reproduzir artificialmente as paralisias que acometiam as histéricas (Freud, 1996d/1905) com o objetivo de provar sua hipótese de que na histeria não havia uma determinação orgânica. Para ele, as paralisias observadas nesse estado eram resultantes de representações que dominavam o cérebro e ditavam seu funcionamento. Haveria, portanto, algo de fisiológico, embora não definido, que determinava o decurso dos sintomas. A noção que então se impunha era a de trauma, e o rastreamento das alterações cerebrais daí decorrentes que escapavam à anatomia patológica deveria ser feito pela hipnose (Charcot como citado em Birman, 2012). Assim, não haveria um trauma anatômico, antes funcional e dinâmico.

De acordo com Chertok e Stengers (1989), Charcot deparava-se, na histeria, com os mesmos efeitos observados pela comissão designada pelo rei Luís XVI para dissecar as crises mesméricas e, de igual modo, estava impossibilitado de atribuir a qualquer agente material o determinismo causal do fenômeno. Entretanto, longe de recuar no estudo do fenômeno, Charcot propôs um novo entendimento e, a um só golpe, resgatou a histeria do campo da simulação e reabilitou a hipnose, um século depois, ao circuito médico/científico, descartada e mantida a distância desde Mesmer (Birman, 2012; Ellenberg, 1970; Zweing, 2017).

Quanto à terceira linha, cujas ideias são creditadas a August Liébeault e seguidores, como Bernheim e Auguste Forel (1848-1931), 
os fenômenos da hipnose constituíam efeitos psíquicos, efeitos de ideias provocadas, sem, no entanto, serem resultantes de estímulos externos, mas da sugestão (Ellenberger, 1970). Comparando a hipnose ao estado de sono natural, seguindo os passos de Liébault, para quem a distinção entre hipnose e o sono normal se resumia à adição, na hipnose, da relação entre o hipnotizado e o hipnotizador, Bernheim atribuiu a condição de possibilidade da hipnose, bem como a do sono, à existência de uma "sugestionabilidade humana normal" (Freud, 1996a/1988-9, p. 52), cuja explicação se achava num "estado de preparação mental e pela expectativa do sono" (Freud, 1996a/1988-9, p. 52).

Segue-se desta concepção a ancoragem do fator explicativo da hipnose na sugestão, definida por Bernheim como "uma ideia concebida pelo operador, captada pelo hipnotizado e aceita por seu cérebro" (Freud, 1996a/1888-9, p. 48.). Assim, em seu corpo teórico, a "sugestão é erigida como núcleo do hipnotismo e chave para sua compreensão" (Freud, 1996a/1988-9, p. 48).

Com essas duas teorias Freud entrará em contato e fará uso tanto da hipnose quanto da sugestão para, posteriormente, lançar mão do que seria seu próprio método, aperfeiçoando a técnica e propondo uma mudança epistêmica que recobrará à hipnose a posição de fenômeno explicável e admissível não apenas para pensar a relação entre dois sujeitos, mas, também, a formação grupal.

\section{Freud e as práticas sugestivas: rumo à construção da Psicanálise}

Quando Freud começou a lidar com as doenças nervosas apenas um percurso lhe era possível enquanto médico: conhecê-las a partir do exame clínico. Entretanto, os caminhos da medicina, com os métodos e técnicas peculiares a esse campo, lhe eram pouco atrativos. As sinuosidades da alma humana e suas relações tiveram um apelo maior à curiosidade do jovem médico. Neste intento, Freud foi a Paris tentar aprender e apreender o que escapava ao saber médico, o que a dissecação do cérebro não the pôde responder.

Com Charcot, em 1885, Freud se aproximou da hipnose. A percepção de que a histeria escapava ao modelo anatômico-clínico, por não existir qualquer lesão localizável no cérebro das enfermas, impunhase, segundo Birman (2012), utilizando-se do conceito proposto por Bachelard, como obstáculo epistemológico à neuropsiquiatria e desnudava os impasses teóricos e clínicos do modelo dominante de então. Se a histeria desconhecia a anatomia, como afirmara Charcot (Freud, 1996d/1905), fazia-se necessário a busca de um novo ordenamento dos fatos. 
Como obstáculo, a histeria deveria ser superada em favor do avanço da ciência. Se o problema era de ordem psicológica, necessário seria, portanto, redefinir a noção de causa psicológica (Chertok \& Stengers, 1989).

Tal redefinição, cara ao meio científico, parecia encontrar ancoradouro, sobretudo na aproximação feita por Freud com Bernheim em 1889, cuja teoria rompia em definitivo com qualquer causa anatômica na histeria, a qual era definida, por seu turno, como "efeito da sugestionabilidade sobre o sujeito" (Birman, 2012, p. 55). A cura, nesse caso, seria possível mediante aplicação, pelo médico, do efeito contrário, a saber, a contrassugestão (Birman, 2012).

Isto posto, Freud herdará de Charcot a ideia de trauma, que imprimiria traços psíquicos duradouros, determinantes e constituintes do que posteriormente seria denominado de aparelho psíquico. Entretanto, tal qual exposto por Bernheim, antes de ser provocado por uma lesão cerebral, o trauma seria causado no encontro do sujeito com o outro.

De volta à Viena, Freud encontra Josef Breuer (1842-1925), médico, antigo companheiro de laboratório, que havia tratado de uma paciente histérica entre 1880 e 1882 . Os relatos de Breuer sobre o caso produziram grande impressão em Freud. Ana O., como ficou conhecida a paciente, descobriu que ao falar sobre os afetos contidos, talking cure (Freud \& Breuer, 1996/1895, p. 37), e varrer a sujeira que permeava seu inconsciente, chimney-sweeping (Freud \& Breuer, $1996 / 1895$, p. 38), conseguia ficar mais tranquila das alucinações e angústias que a atormentavam. Breuer soube esperar, escutar e entender que, para além do que a paciente despejava em palavras, algo se ocultava.

A paciente sabia que, depois que houvesse dado expressão a suas alucinações, perderia toda a sua obstinação e aquilo que descrevia como sua "energia"; enquanto, após um intervalo relativamente longo, ficava de mau humor, recusava-se a falar, sendo eu obrigado a superar sua falta de disposição encarecendo e suplicando, e até usando recursos como repetir uma fórmula com a qual ela estava habituada a iniciar suas histórias. (Freud \& Breuer, 1996/1895, p. 38).

Ana O. rememorava cenas e fatos aos quais não foi possível um escape dos afetos correlatos, ao que permanecia, deste modo, afeto e representação desgarrados. A cada afeto reprimido se formou um sintoma que, de maneira paulatina, pela recordação, ao entrelaçar o afeto à representação, foram os sintomas, um a um, desvanecidos. Segundo Freud (1996j/1925), ao falar sobre o Caso Ana O. , no Estudo autobiográfico, "os sintomas tinham um significado e eram resíduos ou reminiscências daquelas situações emocionais" (p. 12). 
Ainda, prossegue o autor, pela "hipnose ela de pronto descobria a ligação que faltava" (p. 12).

Freud começou a trabalhar com Breuer em busca dessa região obscura e fronteiriça em que se situava a histeria. Usavam a hipnose para fazer falar o que não se dizia. Não era cura, mas meio pelo qual os afetos podiam escorrer e ganhar algum sentido. Experiência catártica.

Entretanto, o uso da hipnose não durou muito. Em 1891, quando, após acordar do sono hipnótico, uma das pacientes de Freud e Breuer, Caecilie M. (Ana Von Lieben), passou os braços em torno do pescoço Freud, o médico vianense foi sagaz em perceber que o gesto não Ihe dizia respeito, nada tinha a ver com seus "encantos pessoais irresistíveis" (Freud, 1996j/1925, p. 17). Antes, direcionava-se a um outro interposto entre os dois. Ao falar pelo corpo o que não conseguia expressar em palavras, Ana $V$. Lieben trazia à baila sentimentos cuja expressão estava suprimida e, mediante a possibilidade, no encontro com o outro, ganhava forma e contorno.

As experiências psíquicas das mulheres analisadas por Breuer e Freud expunham os desejos inconsciente e os fantasmas conexos, que teciam a realidade psíquica (Laplanche \& Pontalis, 1967) e contrapunham-se à realidade material. Estava esboçado o conflito fundante do aparelho psíquico - condição de possibilidade da divisão psíquica em distintas tópicas - e das defesas contra os materiais oriundos desses diversos lugares. Freud atingia a compreensão dos processos mentais inconscientes, da energia psíquica deslocável e do que, posteriormente, seria o novo método psicanalítico, a saber, a transferência.

As aprendizagens com Charcot, Bernheim e Breuer deram os fios dos fatos com os quais Freud costurou a concretude da psicanálise. A histeria, até então entendida como adoecimento somático, passou à categoria de transtorno causado por um conflito psíquico, inconsciente, em cuja base estavam os desejos recalcados, incompatíveis com a moral social. A fala e as relações de sentido e cura por ela alinhavadas ganharam cada vez mais espaço na teoria em construção.

Em 1890, no texto Tratamento Psíquico, Freud dará à palavra um lugar privilegiado nos processos de cura, cujo princípio repousaria na influência que uma pessoa exerce sobre outra, expondo, deste modo, a "magia das palavras" (Freud, 2017a/1890, p. 31), o que estas carregam de imponderável, posto que, para Freud, "são os mais importantes mediadores da influência que uma pessoa quer ter sobre outra" (p. 31). Entretanto, a palavra, sozinha, seria nula, um sopro perdido na imensidão do nada, só que encarnada na figura de poder representada pelo médico, cuja influência, aliada à disposição do paciente em obter a cura e a confiança no método utilizado, conduziria o paciente a um estado psíquico favorável à cura, estado 
em que o anímico teria efeito potencializado sobre o físico. Deste modo, a influência não é apresentada como a cura para as doenças nervosas, antes um acesso privilegiado, por meio do psíquico, ao físico, mediante a influência do médico a partir das palavras. Freud destrincha o mecanismo da influência como base para os processos de cura.

Assim, o jovem médico vienense propõe um tratamento que se daria não pela consciência, mas pela palavra. Nem no somático, privilegiado pela medicina, nem na consciência, privilegiada pelas psicologias de então, estaria a causa do adoecimento e, por conseguinte, a cura para os distúrbios psíquicos. Fazia-se necessário ir além, à fronteira entre os dois registros, de modo que, para alcançar os sintomas físicos causados pelo trauma psíquico, Freud ofereceu a linguagem e seu "poder mágico" (Freud, 2017a/1890, p. 19), há muito presente e explorado pelas religiões, pela medicina antiga, pelos tratamentos hipnóticos e pela sugestão.

\section{Transferências}

Ainda, no tratamento anímico, Freud (1890) chama a atenção para a intensa relação estabelecida entre hipnotizador e hipnotizado, de modo que o mundo externo esfacela-se em interesses para este último, restando o hipnotizador como único e intenso estímulo. Outro fator, não menos importante, observado por Freud, fora a completa submissão às ordens do hipnotizador, reduzido, o hipnotizado, a uma obediência cadavérica. Percepção que leva Freud a comparar a hipnose à relação amorosa, no que congregam de entrega e confiança devota.

Entretanto, como obstáculo ao potente método da sugestão e da hipnose, levantou-se a resistência do paciente contra a submissão completa ao hipnotizador, uma vez que o hipnotizado estaria disposto a fazer apenas "pequenos sacrifícios" (Freud, 1996/1890, p. 42), expondo as forças que geraram e mantêm os sintomas e contra as quais combate a sugestão.

Somente em 1905, na análise do caso Dora, portanto 15 anos após o Tratamento Psíquico, que Freud (1996d/1905) fará a junção entre sintoma, resistência e sexualidade para construir um novo conceito: "as transferências" (p. 71). Neste momento da teorização, as transferências, no plural, dizem respeito às fantasias e desejos despertados e tornados conscientes durante o tratamento, entretanto deslocadas em seu objeto, visto que o médico é posto a serviço da realidade psíquica, em lugar de uma pessoa anterior na vida do paciente.

Neste ponto de desenvolvimento teórico a transferência não era parte essencial da relação terapêutica (Laplanche \& Pontalis, 1967). O que 
está posto em 1905 é a descoberta da transferência como aliada à resistência com o objetivo de tornar o material reprimido inacessível à consciência.

\section{A construção do dispositivo terapêutico: transferência e libido}

Em A dinâmica da transferência, Freud (1996f/1912) explana os achados psicanalíticos sobre o surgimento da transferência no processo terapêutico e a importância que ela assume no trabalho analítico. Para o autor, nossas vidas amorosas são guiadas por "clichês estereotipados" (p. 111). Dos impulsos libidinais, apenas uma parte alcança pleno desenvolvimento, cuja orientação se dará em direção à realidade externa e comporá nosso consciente. Outra parte fica retida no curso deste processo, subsidiando, assim, 0 inconsciente. Essa libido não satisfeita, que não alcançou pleno nível de desenvolvimento, encontra-se "pronta por antecipação" (Freud, 1996f/1912, p. 112) e, mediante as circunstâncias externas e a natureza do objeto amoroso, serão repetidas e reimpressas no decorrer da vida. É desta maneira que responderá Freud à disposição do paciente em colar à pessoa do médico desejos e fantasias, recorrendo a protótipos e o inscrevendo numa das séries psíquicas anteriormente formadas pelo paciente.

Neste ponto se abre uma nova compreensão do fenômeno da transferência. Entendida até então como deslocamento da libido de um objeto a outro, passa a se referir aos complexos infantis que subsidiam o complexo de Édipo. Tal noção será acentuada no decorrer do desenvolvimento da teoria psicanalítica, e, em 1938, no Esboço de Psicanálise, fica patente a importância do complexo nuclear da neurose no surgimento da transferência. A repetição, na transferência, é de um protótipo infantil, em que a "reencarnação" (Freud, 1996m/1938, p. 116) é de alguma figura importante, como o pai e/ou a mãe, cuja autoridade é inquestionável na vida do sujeito. Assim, o lugar do analista, quando posto a serviço da representificação de tais figuras, reveste-se do "poder que 0 superego exerce sobre o ego, visto que os pais foram, como sabemos, a origem do seu superego" (Freud, 1996m/1938, p. 116). Através da transferência chega-se ao núcleo da problemática, pois, servindo como resistência, em que se atua o conflito ao invés de rememorá-lo, a transferência mantém a libido aprisionada aos seus objetos imaginários e desejos descolados, de modo que é possível colher o conflito primordial, em estado bruto, atuando em suas especificidades.

O que se tem é um teatro representacional no qual o investimento libidinal inclui o médico numa das séries psíquicas pré-formadas pelo paciente (Freud, 1996f/1912), transformando a neurose comum em 
neurose de transferência. Será no manejo da situação analítica, através da transferência, que se buscará o núcleo das pulsões patogênicas, inconscientes para o paciente (Freud, 1996g/1914). Entretanto, desta cena também provém os maiores obstáculos ao trabalho terapêutico, pois o paciente agarre-se à relação com 0 médico como se fosse real e atual, enquanto que a causa do conflito entre o desejo e a consciência permanece, ela própria, inacessível.

Em A dinâmica da transferência, Freud (1996f/1912) é peremptório ao afirmar que o sucesso da análise se baseia na sugestão, definida como "a influência de uma pessoa por meio de fenômenos transferenciais" (p. 117). Nas Conferências introdutórias de 1917, o autor ressalta a importância da influência que um sujeito exerce sobre o outro. Em seus dizeres, "um homem só é acessível, também a partir do aspecto intelectivo, desde que seja capaz de uma catexia libidinal de objetos" (Freud, 1996h/1917, p. 141). Já no ano de 1921, em Psicologia das massas e análise do eu, e em 1925, no texto Um estudo autobiográfico, Freud (1996i/1921, 1996j/1925) defini a transferência como sugestão.

Entretanto, se na sugestão a manutenção da relação transferencial é desejável, no trabalho terapêutico há que se induzir o paciente à realização do trabalho psíquico em que o psicanalista deve tornar a transferência consciente para o paciente, convencendo-o de que a atitude transferencial por ele adotada se baseia na reexperimentação de relações emocionais cuja origem remonta às primeiras ligações de objeto durante o período reprimido da infância. Dessa feita, transforma-se a "arma mais forte da resistência em melhor instrumento do tratamento analítico" (Freud, 1996j/1925, p. 27). É na resolução da transferência que se achará a diferença entre o tratamento analítico e o tratamento pela mera sugestão, ou seja, para se diferenciar dos tratamentos sugestivos, faz-se necessário, à prática psicanalítica, destruir o lugar do analista ao final da análise (Freud, 1996e/1905， 1996f/1912， 1996g/1914，1996h/1917, 1996i/1921).

Ao tematizar o dispositivo da transferência, fundamentado na teoria do inconsciente, Freud abre o campo da psicanálise para a relação do sujeito com o outro. As experiências de Freud na Salpêtrière e em Nancy o fizeram resgatar a intersubjetividade postulando o campo do psíquico marcado pelo "campo dialógico com o outro" (Birman, 1994, p. 36). Nesta empreitada, as relações de causalidade anteriormente buscadas cederam espaço às relações de sentido, marcando o caráter hermenêutico da psicanálise, alocando-a nos discursos da cultura tal qual a filosofia (Birman, 1994). Assim, ao postular outro registro não mais alicerçado na representação e na consciência, mas na investigação a partir da linguagem - investida no circuito da troca dialógica com o outro - Freud marca uma radicalidade em relação à hipnose e à sugestão de que se servira, posto que retira o sujeito do 
campo da passividade em que se via embotado em relação ao médico/hipnotizador/magnetizador (Birman, 1994, 2012).

Esta posição marca uma "descontinuidade" (Foucault, 2008, p. 35) histórica e ética da obra freudiana em relação aos conceitos advindos desde "a primeira psiquiatria dinâmica" (Roudinesco, 2004, p. 5) iniciada por Mesmer e transformada em hipnotismo no decorrer dos anos. Longe de estabelecer uma linearidade histórica com esses "sistemas de pensamento" (Foucault, 2008, p. 30), cuja resultante seria a determinação de uma origem do pensamento freudiano, a prática clínica, centrada no inconsciente e na linguagem, expõe o caráter irreconciliável dos pressupostos que sustentam a cura. A multiplicidade dos fatos e a dispersão dos acontecimentos no surgimento do saber psicanalítico desenham seu traço genealógico, e não histórico, cujas descontinuidades produziram efeitos no campo da ciência e da política, respectivamente.

Deste último campo resulta um espaço fértil para pesquisas e estudos posteriores. Ao alargar o campo de ação da influência e da sugestão para os fenômenos sociais, em Psicologia das massas e análise do eu, - Mal-estar na civilização e na carta a Einstein, editada em Por que a guerra?, Freud (1996i/1921, 1996k/1930, 1996l/1933) reserva à relação do sujeito com o outro o mote de sua teorização. Será nessa relação que o autor buscará respostas para os problemas sociais, como a guerra, bem como a possibilidade de empoderamento do sujeito face às figuras de poder. Entre vontade consciente $e$ submissão, influência e resistência, que a teoria psicanalítica, baseada no inconsciente, e a prática clínica, possível mediante a transferência, interrogam o homem em seu desejo de ser sugestionado - quer busque a cura para as doenças que o aflige, quer busque soluções para os males sociais - , questão essa colocada desde o século XVI, por La Boetiè (1982/1563) no célebre Discurso sobre a servidão voluntária. Logo, para além de uma genealogia das práticas curativas, a influência nos coloca na pista de fenômenos humanos que ainda soam enigmáticos, como a política das massas.

\section{Conclusão}

Buscamos, neste artigo, fazer um percurso pelas principais práticas terapêuticas baseadas na influência com o objetivo de estabelecer relações entre o contexto político da modernidade nascente e a transformação da influência em paradigma terapêutico no século XIX, depois de ter sido execrada, por meio do magnetismo animal, do campo da ciência e da cultura, um século antes na França prérevolução. Do fluído magnético à libido freudiana, passando pela sugestão, hipnose e transferência, o quê está no cerne da questão é o dispositivo da influência como paradigma terapêutico cuja 
emergência se evidencia no campo político. Se essa hipótese faz sentido, achamo-nos autorizados a afirmar que a psicanálise já nasce como prática política na medida em que traz para as trincheiras do saber médico a pulsação da vida e da história.

A partir desse pressuposto entendemos a afirmação de Freud (1996i/1921), em Psicologia das Massas e análise do Eu, segundo a qual toda a psicologia, antes de ser individual, é social, entendimento, por sua vez, que nos arremessa em uma nova questão: se, no campo da clínica, faz-se necessária a dissolução da transferência, enquanto relação de dependência e poder, para que haja um efetivo processo terapêutico, podemos nos perguntar, então, quais os mecanismos que podem pautar uma postura ética no campo político, cuja relação entre os diferentes componentes da humanidade não se dê pelo viés da soberania e do exercício de poder? Em outros termos, a partir do dispositivo da transferência, que modelo de política a psicanálise nos anunciaria?

\section{Referências}

Barros, R. B., \& Josephson, S. C. (2008). A invenção das massas: a psicologia entre o controle e a resistência. In A. M. Jacó-Vilela, A. A. L Ferreira, \& F. T. Portugal (Org.), História da Psicologia: rumos e percursos (2a ed., pp. 441-462). Rio de Janeiro: Nau Editora.

Bachelard, G. (1996). A formação do espírito científico: contribuições para uma psicanálise do conhecimento (pp. 141-158). Rio de Janeiro: Nau Editora. (Obra original publicada em 1938).

Birman, J. (1994). Psicanálise, ciência e cultura. Rio de Janeiro: Jorge Zahar.

Birman, J. (2012). Modernismo e psicanálise: a problemática da influência na crítica freudiana do dispositivo da hipnose e na constituição do dispositivo da transferência. Revista brasileira de psicanálise, 46(2), 47-64.

Birman, J., \& Coelho, D. M. (2014). A transferência na pesquisa em psicanálise - um ponto de vista ético. In J. Birman, D. Kupermann, E. L. Cunha \& L. Fulgêncio (Org.), A fabricação do humano, psicanálise, subjetivação e cultura (pp. 123-135). São Paulo: Zagodoni.

Bocca, F. V. (2011). Grupo social como hipnose exaltada. Revista Digital AdVerbum, 6(2), 167-176. Recuperado de http://www.psicanaliseefilosofia.com.br/adverbum/vol6_2/06_0 2_05gruposocialhipnose.pdf

Chertok, L., \& Stengers, I. (1989). O Coração e razão: a hipnose de Lavoisier a Lacan. Rio de janeiro: Jorge Zahar. 
Ellenberger, H. F. (1970). The discovery of the unconscious: the history and evolution of dynamics psychiatry. New York: Basic Books.

Figueiredo, P. H. (2005). Mesmer, a ciência negada e os textos escolhidos. Bragança Paulista: Lachâtre.

Foucault, M. (1977). O nascimento da clínica (R. Machado, Trad.). Rio de Janeiro: Editora Forense universitária. (Obra original publicada em 1963).

Foucault, M. (2008). A arqueologia do saber (7a ed., L. F. B. Neves, Trad.). Rio de Janeiro: Editora Forense universitária. (Obra original publicada em 1969).

Freud, S. (1996a). Prefácio à tradução de La Suggestion, de Bernheim. In S. Freud, Edição Standard brasileira das obras psicológicas completas de Sigmund Freud (vol. 1, pp. 107-124). Rio de Janeiro: Imago. (Obra original publicada em 1988-9).

Freud, S. (1996b). Resenha de Hipnotismo, de August Forel. In S. Freud, Edição Standard brasileira das obras psicológicas completas de Sigmund Freud (vol. 1, pp. 125- 140). Rio de Janeiro: Imago. (Obra original publicada em 1899).

Freud, S. (1996c). Tratamento psíquico. In S. Freud, Edição Standard brasileira das obras psicológicas completas de Sigmund Freud (vol.7, pp. 271- 292). Rio de Janeiro: Imago. (Obra original publicada em 1890).

Freud, S. (1996d). Fragmento da análise de um caso de histeria. In S. Freud, Edição Standard brasileira das obras psicológicas completas de Sigmund Freud (vol.7, pp. 13-116). Rio de Janeiro: Imago. (Obra original publicada em 1905).

Freud, S. (1996e). Sobre a psicoterapia. In S. Freud, Edição Standard brasileira das obras psicológicas completas de Sigmund Freud (vol. 7, pp. 245-257). Rio de Janeiro: Imago. (Obra original publicada em 1905)

Freud, S. (1996f). A dinâmica da transferência. In S. Freud, Edição Standard brasileira das obras psicológicas completas de Sigmund Freud (vol. 12, pp. 109-119.). Rio de Janeiro: Imago. (Obra original publicada em 1912).

Freud, S. (1996g). Recordar, repetir, elaborar. In S. Freud, Edição Standard brasileira das obras psicológicas completas de Sigmund Freud (vol. 12, pp. 161-171). Rio de Janeiro: Imago. (Obra original publicada em 1914).

Freud, S. (1996h). Conferências Introdutórias. In S. Freud, Edição Standard brasileira das obras psicológicas completas de Sigmund Freud (vol. 16, pp. 251-475). Rio de Janeiro: Imago. (Obra original publicada em 1917).

Freud, S. (1996i). Psicologia de grupo e análise do ego. In S. Freud, Edição Standard brasileira das obras psicológicas completas de 
Sigmund Freud (vol. 18, pp. 77-153). Rio de Janeiro: Imago. (Obra original publicada em 1921).

Freud, S. (1996j). Um estudo autobiográfico. In S. Freud, Edição Standard brasileira das obras psicológicas completas de Sigmund Freud (vol. 20, pp. 10-77). Rio de Janeiro: Imago. (Obra original publicada em 1925).

Freud, S. (1996k). O Mal-estar na civilização. In S. Freud, Edição Standard brasileira das obras psicológicas completas de Sigmund Freud (vol. 21, pp. 65-151). Rio de Janeiro: Imago. (Obra original publicada em 1930).

Freud, S. (1996I). Por que a guerra?. In S. Freud, Edição Standard brasileira das obras psicológicas completas de Sigmund Freud (vol. 22, pp. 189-208). Rio de Janeiro: Imago. (Obra original publicada em 1933).

Freud, S. (1996m). Esboço de psicanálise. In S. Freud, Edição Standard brasileira das obras psicológicas completas de Sigmund Freud (vol. 23, pp. 151-207). Rio de Janeiro: Imago. (Obra original publicada em 1938).

Freud, S. \& Breuer. (1996). Estudos sobre a histeria. In S. Freud, Edição Standard brasileira das obras psicológicas completas de Sigmund Freud. (vol. 2.). Rio de Janeiro: Imago. (Obra original publicada em 1893-1895).

Freud, S. (2017a). Tratamento psíquico. In Fundamentos da clínica psicanalítica, Obras incompletas de Sigmund Freud (C. Dornbusch Trad., pp. 19-46). Belo Horizonte: Autêntica. (Obra original publicada em 1890).

Freud, S. (2017b). Observações sobre o amor transferencial. In Fundamentos da clínica psicanalítica, Obras incompletas de Sigmund Freud (C. Dornbusch Trad., pp. 165-180). Belo Horizonte: Autêntica. (Obra original publicada em 1915).

Freud, S. (2017c). A questão da análise leiga: conversa com uma pessoa imparcial. In Fundamentos da clínica psicanalítica, Obras incompletas de Sigmund Freud (C. Dornbusch Trad., pp. 205290). Belo Horizonte: Autêntica. (Obra original publicada em 1926).

Hesíodo. (1995). Theogonía. In J. Torrano, Teogonia: a origem dos deuses (3a ed., J. Torrado Trad.). São Paulo: Iluminuras. (Obra original s.d.).

La Boétie, E. (1982). Discurso sobre a servidão voluntária. São Paulo: Brasiliense. (Obra original publicada em 1563).

Laplanche, J \& Pontalis, J-B. (1967). Vocabulário de Psicanálise. São Paulo: Martins fontes.

Mesmer, F. A. (2005). Memória sobre a descoberta do magnetismo animal. In P. H. Figueiredo, Mesmer, a ciência negada e os textos escolhidos. (A. Glerean, Trad.). Bragança Paulista: Lachâtre. (Obra original publicada em 1779). 
Monteiro, D. B. R., \& Jacó-Vilela, A. M. (2008). Fios e sedução: os primórdios "psi" nas terapias para corpos e mentes perturbadas". In A. M. Jacó-Vilela, A. A. L Ferreira, \& F. T. Portugal (Org.), História da Psicologia: rumos e percursos (2a ed., pp. 141-158). Rio de Janeiro: Nau Editora.

Neubern, M. S. (2007). Sobre a condenação do magnetismo animal: revisitando a história da psicologia. In Psicologia: Teoria e Pesquisa, 23(3), 347-356. Recuperado de: http://www.scielo.br/scielo.php?pid=S0102-

37722007000300015\&script=sci_arttext

Nietzsche, F. (2012). A gaia ciência (P. C. Souza, Trad.). São Paulo: Companhia das letras. (Obra original publicada em 1882).

Roudinesco, E. (2004). Henri Ellenberger e a descoberta do inconsciente. Revista Latino-americana de psicopatologia fundamental, 8(4), 587-595.

Roudinesco, E., \& Plon, M. (1998). Dicionário de Psicanálise (V. Ribeiro, V., \& L. Magalhães, Trad.). Rio de Janeiro: Jorge Zahar.

Torrano, J. (1995). Três fases e três linhagens. In Teogonia: a origem dos deuses (3a ed., pp. 40-56). São Paulo: Iluminuras.

Zweing, S. (2017). A cura pelo espírito: em perfis de Franz Anton Mesmer, Mary Baker Eddy e Sigmund Freud. Rio de Janeiro: Zahar. (Obra original publicada em 1930).

\section{Endereço para correspondência \\ Tatiane de Andrade}

Universidade Federal do Rio de Janeiro - UFRJ

Programa de pós-graduação em Teoria Psicanalítica

Av. Pasteur, 250, Pavilhão Nilton Campos, Urca, CEP 22299-240, Rio de Janeiro RJ, Brasil

Endereço eletrônico: tatiandrade.aju@gmail.com

Recebido em: 04/11/2018

Reformulado em: 08/03/2019

Aceito em: 08/03/2019

\section{Notas}

* Doutoranda no Programa de Pós-graduação em Teoria Psicanalítica pela Universidade Federal do Rio de Janeiro. Mestre em Psicologia Social e Política pela Universidade Federal de Sergipe. Graduada em Psicologia pela Universidade Federal de Sergipe.

Financiamento: Coordenação de Aperfeiçoamento de Pessoal de Nível Superior CAPES.

Este artigo de revista Estudos e Pesquisas em Psicologia é licenciado sob uma Licença Creative Commons Atribuição-Não Comercial 3.0 Não Adaptada. 